\title{
Percepção de profissionais de Psicologia sobre a assistência oferecida aos usuários de Centros de Atenção Psicossocial
}

\section{Perception of Psychology professionals about the assistance offered to Psychosocial Care Centers users}

\section{Percepción de los profesionales de Psicología sobre la asistencia ofrecida a los usuarios de los Centros de Atención Psicosocial}

Recebido: $28 / 10 / 2019$

Aprovado: 15/04/2020

Publicado: 01/08/2020
Isabel Cristina Carniel ${ }^{1}$ Tamys Duran ${ }^{2}$

Ana Carolina da Silva Oliveira ${ }^{3}$ Sandra Cristina Pillon 4 Manoel Antônio dos Santos 5

Este estudo teve por objetivo examinar a percepção de profissionais de Psicologia sobre a assistência oferecida aos usuários de álcool e outras drogas. Trata-se de uma pesquisa descritiva, exploratória, de abordagem qualitativa, realizada em quatro municípios da região noroeste de São Paulo, no primeiro semestre de 2018. Os dados foram coletados por meio de entrevista semiestruturada realizada com sete profissionais vinculados a quatro Centros de Atenção Psicossocial Álcool e outras Drogas. Os participantes eram majoritariamente do sexo feminino, com idades entre 29 e 56 anos, casados, e haviam se graduado entre cinco e 35 anos. Os relatos foram submetidos à análise de conteúdo, sendo destacadas três categorias temáticas: participação familiar no tratamento: a família é percebida como fonte de apoio, quando presente de maneira efetiva no espaço de tratamento; dificuldade de adesão ao tratamento: é ressaltada a elevada incidência de desistência do tratamento por parte dos usuários; adicção à droga como sintoma do vínculo adoecido: os prejuízos físicos e psíquicos identificados são compreendidos como resultantes da psicopatologia das configurações vinculares. 0 fortalecimento dos vínculos e da rede pessoal de apoio dos usuários é apontado como estratégia fundamental no contexto do cuidado em saúde.

Descritores: Transtornos relacionados ao uso de substâncias; Serviços de saúde; Usuários de drogas; Assistência integral à saúde.

This study aimed to examine the perception of Psychology professionals about the assistance offered to users of alcohol and other drugs. This is a descriptive, exploratory research with a qualitative approach, carried out in four municipalities in the Northwest region of the state of São Paulo, Brazil, in the first semester of 2018. Data were collected through semistructured interviews conducted with seven professionals linked to four Psychosocial Care Centers of Alcohol and Other Drugs. The participants were mostly female, aged between 29 and 56 years old, married, and had graduated between five and 35 years prior. The reports were submitted to content analysis, with three thematic categories being highlighted: family participation in treatment: the family is perceived as a source of support, when present effectively in the treatment space; difficulty in adhering to treatment: the high incidence of users giving up treatment is highlighted; addiction to the drug as a symptom of sick bond: the physical and psychological damage identified are understood to result from the psychopathology of bond configurations. The strengthening of bonds and personal support network of users is highlighted as a fundamental strategy in the context of health care.

Descriptors: Substance-related disorders; Health services; Drug users; Comprehensive health care.

Este estudio tuvo por objeto examinar la percepción de los profesionales de la Psicología sobre la asistencia que se ofrece a los usuarios de alcohol y otras drogas. Se trata de una investigación descriptiva, exploratoria y de enfoque cualitativo, realizada en cuatro municipios de la región noroeste de São Paulo, Brasil, en el primer semestre de 2018. Los datos se recogieron mediante una entrevista semiestructurada con siete profesionales vinculados a cuatro Centros de Atención Psicosocial de Alcohol y Otras Drogas. Los participantes eran en su mayoría mujeres, con edades comprendidas entre 29 y 56 años, casadas y que se habían graduado entre cinco y 35 años atrás. Los informes se sometieron a un análisis de contenido y se destacaron tres categorías temáticas: participación de la familia en el tratamiento: la familia se percibe como una fuente de apoyo, cuando está efectivamente presente en el espacio de tratamiento; dificultad de adherencia al tratamiento: se destaca la alta incidencia de abandono del tratamiento por parte de los usuarios; drogadicción como síntoma del vínculo enfermo: los daños físicos y psíquicos identificados se entienden como resultado de la psicopatología de las configuraciones de los vínculos. El fortalecimiento de los vínculos y la red de apoyo personal de los usuarios se señala como una estrategia fundamental en el contexto de la atención en la salud.

Descriptores: Trastornos relacionados con sustancias; Servicios de salud; Consumidores de drogas; Atención integral de salud.

1. Psicóloga. Mestre e Doutora em Psicologia. Professora Titular da Universidade Paulista (UNIP), Ribeirão Preto, SP, Brasil. ORCID: 0000-0002-4189-128X E-mail: isabel.carniel@docente.unip.br

2. Psicóloga. Ribeirão Preto, SP, Brasil. ORCID: 0000-0003-4475-5723 E-mail: tamys_duran@hotmail.com

3. Psicóloga. Ribeirão Preto, SP, Brasil. ORCID: 0000-0003-2127-6746 E-mail: carolinasvaoliveira@gmail.com

4. Enfermeira. Especialista em Dependência Química. Mestre em Gastroenterologia. Doutora em Psiquiatria e Psicologia Médica. Professora Titular do Programa de Pós-Graduação em Enfermagem Psiquiátrica da Escola de Enfermagem de Ribeirão Preto da Universidade de São Paulo, Ribeirão Preto, SP, Brasil. ORCID: 0000-0001-8902-7549. E-mail: pillon@eerp.usp.br

5. Psicólogo. Mestre e Doutor em Psicologia Clínica. Livre-Docente em Psicoterapia Psicanalítica. Professor Titular e orientador do Programa de Pós-Graduação em Psicologia da Faculdade de Filosofia, Ciências e Letras e de Ribeirão Preto da Universidade de São Paulo, Ribeirão Preto, SP, Brasil. ORCID: 0000-0001-8214-7767 E-mail: masantos@ffclrp.usp.br 


\section{INTRODUÇÃO}

$\mathbf{N}$

o cenário brasileiro, a assistência aos usuários de drogas atualmente é organizada por meio de uma rede pública de atenção. Essa rede é constituída a partir de um esforço de organização integrada de setores, serviços e profissionais articulados com vistas à oferta de cuidados contínuos, em resposta às necessidades específicas dessa população ${ }^{1}$. Desse modo, os cuidados aos usuários de drogas são organizados em torno de uma rede assistencial de serviços ${ }^{2}$.

Peça central e articuladora dessa rede, os Centros de Atenção Psicossocial (CAPS) são equipamentos de saúde constituídos por uma equipe multiprofissional que presta serviços de saúde pública destinados ao acolhimento e assistência integral de pessoas com transtornos mentais ${ }^{3}$, sendo que, entre os diferentes tipos de serviços, destacam-se os Centros de Atenção Psicossocial Álcool e Outras Drogas (CAPSad).

É função do CAPSad, assim como dos demais CAPS, estimular a integração social e familiar da pessoa em sofrimento mental grave e persistente, além de apoiar os usuários para aquisição de autonomia e restauração de novas possibilidades de viver plenamente a vida, maximizando o bem-estar geral. Dentre os serviços oferecidos no CAPSad destacam-se os atendimentos em grupo.

No CAPSad as atividades grupais, implementadas no âmbito dos projetos terapêuticos individuais, são elaboradas em conformidade com as diretrizes que norteiam o funcionamento do serviço, levando-se em consideração as demandas e expectativas dos participantes. Nesse sentido, destacam-se dois tipos de atividades grupais: os grupos terapêuticos propriamente ditos e os grupos operativos.

Os grupos terapêuticos buscam tratar pessoas com indicação de psicoterapia, ou seja, que podem se beneficiar de estratégias que pressupõem a busca de meios de autoconhecimento e desenvolvimento pessoal, ou que visam à remoção e/ou ao alívio de sintomas relacionados a problemas psíquicos ${ }^{4}$. Já os grupos operativos são dispositivos formados a partir do estabelecimento de objetivos comuns entre seus membros, tendo como eixo estruturante a tarefa grupal. As atividades do grupo operativo devem privilegiar uma aprendizagem que favoreça o progresso dos integrantes, seja no plano individual ou coletivo, por meio do exercício da alternância (rodízio) dos papeis que emergem durante a realização da tarefa grupal ${ }^{4}$.

Um dos pressupostos teóricos que sustentam o trabalho em grupo operativo é o reconhecimento da importância central dos vínculos para a constituição psíquica. E, no caso de grupos no contexto da saúde mental, é importante que seus membros interajam uns com os outros e com o coordenador do grupo. Para que essa interação se fortaleça e fomente as condições que favoreçam transformação e apropriação de conhecimento por todos, é necessário que se incentive o exame dos vínculos que os participantes estabelecem entre si e com o coordenador.

Na perspectiva da Psicologia Social de Pichon-Rivière, o vínculo se estrutura no seio das dinâmicas interpessoais, sendo passível de manejo e aprimoramento por meio do aprender com a experiência. Por esse motivo, o vínculo é considerado instrumento para a compreensão da relação que o indivíduo estabelece consigo mesmo e/ou com outras pessoas, o que pode se repetir nas diferentes configurações vinculares que ele estabelece ao longo da vida 5 .

A qualidade dos vínculos afeta a relação da pessoa consigo mesma, o que por sua vez interfere na sua capacidade de suportar frustrações e enfrentar adversidades ao entrar em contato com a realidade. Também interfere na capacidade de aprender, de ser criativo e sentirse realizado com suas relações e repercussões de suas ações desenvolvidas no mundo, o que se reflete na maneira como o indivíduo se sente participante ativo da comunidade a qual pertence. A consistência do vínculo faz diferença em termos de favorecer com que a pessoa se sinta ou não uma pessoa feliz e ajustada em sua comunidade, família e consigo própria, mesmo quando se encontra sob determinada carga de estresse, limitações e privações, que de resto são inevitáveis por serem fenômenos inerentes ao viver6. 
Os diversos vínculos significativos que o indivíduo constrói ao longo das diversas etapas do ciclo vital resultam na formação de sua rede social significativa. Devido à intersecção e porosidade da fronteira existente entre os diversos membros dessa rede com outras redes, os indivíduos tanto podem influenciar como ser influenciados por elas. Rede, nesse contexto, pode ser entendida como uma estrutura sem fronteiras, um sistema aberto e permeável formado por elos e pontos de apoio, um conjunto de pessoas autônomas que somam recursos e partilham ideias acerca de interesses e valores comuns ${ }^{1,6}$.

Nesse sentido, as redes de apoio social constituem conjuntos de vínculos estabelecidos pelo indivíduo com as pessoas emocionalmente significativas para ele, ou seja, aquelas com quem se processa uma interação regular, como conversas e trocas que levam o sujeito a se sentir real e propenso a buscar uma adaptação ativa à realidade ${ }^{5}$. As redes se verticalizam em grupos concretos, que podem ser personificados na família, nos amigos, colegas de trabalho, vizinhos, pessoas que pertencem ao mesmo círculo religioso e comunitário, profissionais de saúde, professores, entre outros. Essas redes servem como fonte potencial de recursos, apoio emocional e informações, e são caracterizadas por fomentarem interações frequentes, apoio significativo e afeto positivo ${ }^{7}$.

Entendendo como se formam os grupos e as redes de suporte social, bem como a importância que essas fontes de apoio têm para a constituição vincular da subjetividade, fica evidente a necessidade de se trabalhar sob um enfoque grupal quando se adota uma perspectiva de promoção e prevenção em saúde mental. Nessa perspectiva, o sujeito pode ser visto em sua totalidade dialética como aquele que não só é influenciado como é, ele próprio, influenciador e transformador de seu meio.

Em um grupo, o que uma pessoa diz, pensa ou sente comunica também algo do conjunto dos integrantes. Quando alguém fica doente, de algum modo está comunicando algo sobre os grupos dos quais participa e as fragilidades dos laços que o conectam aos demais integrantes. Nessa perspectiva, a doença mental pode ser entendida como um fenômeno que emerge da dinâmica intersubjetiva de um grupo familiar e que, portanto, comunica algo que ainda não pôde ser formalizado em palavras, porque ainda não acedeu à simbolização no espaço das configurações vinculares familiares.

O doente pode ser visto como um mensageiro que, de certa forma, dá voz a uma problemática emocional que envolve seu grupo familiar. Assim, ele se torna porta-voz, aquele que denuncia, por meio de seu sofrimento, um outro tipo de desconforto que ainda não logrou ser representado e nomeado, e que encontrou vazão e logrou algum tipo de alívio em uma expressão sintomática vetorizada pelo membro da família que adoece ${ }^{8}$. Vista por esse enquadramento teórico, a pessoa adoecida carrega a patologia vincular do grupo a que pertence.

Nesse contexto, nem sempre quem manifesta a doença é o membro mais fraco e vulnerável do grupo. Por vezes é apenas aquele que personificou uma dramática que pertence ao grupo familiar e sua trama vincular inconsciente. Pichon-Rivière argumenta que o doente é justamente o membro mais forte da organização familiar, eleito precisamente porque se tornou o depositário de grande parte dos conflitos não resolvidos do grupo, assumindo para si uma responsabilidade que deveria ser igualmente reconhecida por todos. 0 indivíduo acometido pelo transtorno mental torna-se, assim, o bode expiatório de seu grupo familiar. Reconhece-se que este é um conceito-chave para a compreensão das raízes do sofrimento psíquico grave e persistente. Ao não suportar mais a depositação grupal maciça, o membro familiar mais sensível sucumbe à doença ${ }^{8,9}$, com a qual, paradoxalmente, denuncia o mal-estar familiar não reconhecido, o que faz dele mártir e vítima sacrificial da família8.

Umas das formas contemporâneas mais salientes pelas quais a patologia do vínculo familiar pode se manifestar é a drogadição. Em uma sociedade excludente e regida pelo consumismo e individualismo extremo, o uso abusivo de substâncias psicoativas pode ser considerado como uma forma de obtenção de prazer imediato que favorece a evasão do 
sofrimento. Muito embora essa promessa nunca se realize de fato, a tentação de se obter uma solução mágica para as complicações do viver é considerável.

Além de dar vazão a um tipo de pensamento onipotente e realizador de desejos, regido eminentemente pelo processo primário, o uso de drogas pode também adquirir um significado adicional de representar uma forma de subversão, contestação e transgressão às normas vigentes. Esse comportamento repercute negativamente na saúde física, psíquica e social do usuário, o que torna fundamental delinear uma análise do contexto vincular familiar e sociocultural subjacente ao aparecimento dos sintomas da drogadição, isento de juízos morais e intenções salvacionistas.

A recuperação do usuário de drogas é favorecida por intervenções que sejam direcionadas à construção de uma rede de apoio que inclui a família, grupos comunitários e amigos. 0 fortalecimento das redes de apoio social se relaciona diretamente com a recuperação da saúde física e mental do indivíduo que se mostra mais vulnerável frente a uma situação de crise ${ }^{7}$.

A aplicação dos grupos no enfrentamento dos transtornos relacionados ao uso de substâncias já conta com uma considerável tradição estabelecida. A sociedade atual é caracterizada pelo individualismo e pela fragilização dos vínculos sociais, que impõe modos de subjetivação que aproximam as pessoas a vivências de extremo desamparo e solidão ${ }^{9}$. Esse individualismo se baseia na busca de prazer imediato, com máxima evitação da dor por meio da incorporação de objetos cujo consumo satura ilusoriamente o desejo humano, ao tamponar a falta, dando ao indivíduo uma falsa sensação de plenitude narcísica. A incorporação física substitui a exigência do trabalho de elaboração simbólica. É como se o ter garantisse ilusoriamente a passagem para o $\operatorname{ser}^{9}$.

As promessas vinculadas à posse de determinadas marcas, grifes, carros e dispositivos eletrônicos, como laptops e aparelhos celulares, são regidas pela mesma lógica que regula o consumo de drogas. Essa dinâmica de funcionamento promete que a dor de existir pode ser sanada quando o indivíduo incorpora objetos dotados de materialidade, principalmente em se tratando de substâncias que prometem maximizar a fruição do gozo ${ }^{9}$. 0 consumo da droga garante ao sujeito uma forma rápida de evasão de situações penosas e angustiantes, ou seja, oferece uma fuga, um atalho bioquímico ante uma realidade sentida como desalentadora e insuportável, que induz sofrimento e amplia a sensação de desamparo.

Por outro lado, a posse do objeto-droga impede o indivíduo de se implicar na procura de sua própria satisfação, ou seja, evita o contato com a falta estruturante e as carências do ser, produzindo profundo isolamento afetivo e alienação social. 0 universo da droga tem como característica a forte presença e o aprisionamento a um presente eternizado, com o não reconhecimento do passado e notável indiferença em relação ao futuro. É relevante lembrar que, nessas circunstâncias, o vínculo insubstituível não é com o outro, mas com a substância, que usurpa o lugar do objeto faltante e assim oblitera a dor da incompletude estrutural que é própria do humano.

A formação de vínculo é necessária em toda forma de comunicação, porém requer um tempo para que se estruture de forma estável nos casos de pessoas em tratamento ambulatorial. Acrescente-se ainda que, na maioria dos casos, com o decorrer do tempo a pessoa busca ajuda por se frustrar na relação com o artefato químico, o que nem sempre garante que ela tenha uma compreensão dos prejuízos que a dependência promove. Nesses casos há uma experiência de rompimento da lua de mel com a droga ${ }^{10}$.

Quando o sujeito que faz uso crônico de substâncias encontra um lugar onde se sente compreendido ao invés de criticado, e onde pode ser percebido pelo outro sem ter que ser igual, seu sentimento de ameaça pode ser amenizado e sua sensação de liberdade é ampliada. A sociedade está adoecida e com isto, promove certos arranjos vinculares que vêm contribuindo maciçamente para o agravamento da doença emocional. Por esse motivo o dispositivo grupal tem sido bastante apreciado e valorizado como uma possibilidade de construção de vínculos mais saudáveis, favorecendo a montagem de uma rede de apoio que verticaliza configurações 
vinculares saudáveis. 0 vínculo é a ferramenta principal do trabalho terapêutico, sendo por isso o melhor aliado do tratamento. Sem uma atenção especial à trama vincular não se pode falar em resultados duradouros para problemas que são eminentemente humanos e, portanto, vinculares ${ }^{11}$.

Em um grupo terapêutico oferecido no cenário do CAPSad, os participantes podem reconhecer o espaço vincular como um recurso de ajuda, no qual todos podem participar com sugestões, ações e afetos que estimulam a gestão e resolução compartilhada de conflitos ${ }^{11}$. No grupo operativo, em sua vertente de técnica de intervenção, tem-se um dispositivo que se afina com os paradigmas atuais em saúde e educação, ao instaurar o sujeito no centro de seu processo de aprendizagem, como sujeito e protagonista ativo na produção de sua saúde, por meio da construção coletiva do conhecimento e dos sentidos que dão significado à experiência humana ${ }^{12}$.

O CAPSad pode ser entendido como um lugar diferenciado e mais apropriado do que o hospital psiquiátrico para o tratamento da adicção, porém os pacientes ainda podem ter dificuldades de se sentirem seguros e pertencentes a outros espaços que não aqueles que são tradicionalmente associados à sua doença, por influência do modelo manicomial anterior à instauração da Atenção Psicossocial ${ }^{13}$.

$\mathrm{Na}$ medida em que se sintam acolhidos e pertencentes ao grupo, os indivíduos entendem que têm um lugar no CAPS, na família e na sociedade. Percebem também que sua participação no grupo não é algo dado e fixo, nem é para sempre, uma vez que o grupo é um organismo dinâmico e temporal, sujeito a metamorfoses constantes que podem mudar sua composição de forma contínua. Os integrantes do grupo também podem experimentar mudanças, ao entrarem em contato com novos sentimentos e emoções, o que possibilita o acesso a novas formas de ser e estar no mundo.

A dependência química deve ser tratada como um condição crônica que extrapola os contornos de um problema médico. É um fenômeno da saúde e, simultaneamente, um problema social, caracterizado por um estado mental e físico que resulta da interação distorcida do usuário com o objeto de sua compulsão. Esse objeto pode se materializar na forma de álcool e/ou de outras substâncias com efeito psicoativo ${ }^{14}$.

No caso da drogadição, a pessoa sofre por sua incapacidade de estar só e, ao mesmo tempo, por apresentar dificuldades de se relacionar com o outro. Por isso pode buscar na substância psicoativa a satisfação que não consegue obter de uma relação real e genuína, mas sem pagar o preço dos supostos riscos associados à intimidade, uma vez que o contato com a realidade em sua dimensão de alteridade é vivido como insuportável ${ }^{15}$. É como se, na adicção a um objeto, houvesse uma tentativa de se defender da dependência de outro ser humano. 0 extremo desse modo adicto de se relacionar é representado pela devoção passional ao objetodroga, justificando uma relação fusional com o outro que, nessa união na qual se dissolvem os limites do eu, deixa de ser considerado em sua alteridade e singularidade ${ }^{15}$.

A diferença entre dependência química e adicção está no fato de que a dependência está voltada para a relação do indivíduo com a substância psicoativa. Já a adicção refere-se à subjetividade do indivíduo e seu modo próprio de se relacionar para além do uso da substância em si. Desse modo, compreender o fenômeno da adicção na perspectiva das configurações vinculares é fundamental para conduzir intervenções potentes com usuários de substâncias psicoativas, tanto em grupo como na modalidade individual, ao propiciar um olhar sensível que vai além das percepções de senso comum, sendo por isso capaz de oferecer acolhimento ao sofrimento dessas pessoas e meios para encorajá-las a desenvolverem seus recursos de transformação.

Dada a importância de que se reveste o trabalho com grupos para o fortalecimento de vínculos saudáveis, uma gama diversificada de intervenções grupais compõe o repertório de práticas conduzidas nos atendimentos realizados nos CAPSad. Parte dessas intervenções está 
sob a responsabilidade de profissionais de Psicologia. Nesse contexto, é relevante conhecer qual a percepção desses profissionais acerca do trabalho realizado.

Os profissionais que operam na lógica da Atenção Psicossocial necessitam ter uma visão abrangente em sua atuação comunitária, em conformidade com o modelo preconizado pela política de saúde, que reconhece o CAPSad como o principal elemento articulador da rede de atendimento a dependentes químicos junto ao Sistema Único de Saúde (SUS) ${ }^{7}$. Indivíduos envolvidos com problemas relacionados ao abuso de substâncias muitas vezes encontram-se excluídos de uma vida social digna, e por isso necessitam de intervenções que contemplem também suas dificuldades de estabelecer e manter vínculos saudáveis, estáveis e duradouros.

Considerando a importância de fomentar reflexões sobre a importância das configurações vinculares na gama de cuidados terapêuticos voltados aos usuários do CAPSad, especialmente os vínculos estabelecidos com a equipe de saúde, este estudo teve por objetivo examinar a percepção de profissionais de Psicologia sobre a assistência oferecida aos usuários de álcool e outras drogas.

\section{MÉTODO}

Trata-se de uma pesquisa descritivo-exploratória, realizada no primeiro semestre de 2018, no contexto dos CAPS Álcool e outras Drogas (CAPSad). Participaram do estudo profissionais de Psicologia que atuavam junto à equipe interdisciplinar nos referidos CAPS de quatro municípios da região noroeste do Estado de São Paulo, a saber: Ribeirão Preto, Sertãozinho, Santa Rita do Passo Quatro e São Joaquim da Barra. Os critérios de elegibilidade dos participantes foram: ser profissional com vínculo de trabalho formal com a instituição e atuar como coordenador de grupos com pacientes com diagnóstico de transtornos por uso de substâncias.

A abordagem escolhida para a condução da pesquisa foi qualitativa, com emprego da entrevista semiestruturada, aplicada individualmente em sala reservada do serviço. Enquanto técnica de coleta de dados, a entrevista possibilita a obtenção de dados referentes aos mais diversos aspectos da vida social e subjetiva do indivíduo. No caso das entrevistas semiestruturadas, nota-se que elas oferecem maior flexibilidade, permitindo que o entrevistador tenha condições de esclarecer o significado das perguntas e que as adapte aos entrevistados e às circunstâncias específicas em que se desenvolve a conversação ${ }^{16}$.

0 roteiro utilizado para conduzir a entrevista semiestruturada foi composto por questões que buscavam conhecer as percepções dos participantes acerca da assistência oferecida, o percurso de tratamento e as configurações vinculares prevalecentes em usuários de álcool e outras drogas. As entrevistas foram audiogravadas e os registros foram posteriormente transcritos na íntegra e literalmente, constituindo o corpus da pesquisa.

A análise dos dados se deu por meio da construção de categorias temáticas, a partir das transcrições literais das falas dos entrevistados. Os relatos foram submetidos à Análise Temática, que seguiu o modelo proposto por Bardin ${ }^{17}$.

A pesquisa foi aprovada pelo Comitê de Ética e Pesquisa (CAAE: 84147518.5.0000.5512; Parecer número: 2.577.592). Na condução do estudo foram respeitados todos os preceitos éticos, conforme determina a Resolução 466/12 do Conselho Nacional de Saúde. As entrevistas só foram consumadas após anuência da coordenação dos CAPSad e assinatura do Termo de Consentimento Livre e Esclarecido pelos participantes. 0 anonimato foi assegurado ao se substituírem seus nomes reais por códigos, que variaram de [P1] a [P7], sendo a letra P a inicial da palavra "participante", e o número subsequente associado à ordem temporal em que foi realizada a entrevista. 


\section{RESULTADOS}

Participaram do estudo sete psicólogos, majoritariamente do sexo feminino, com idades variando entre 29 e 56 anos, casados e graduados entre cinco e 35 anos. A partir da análise do corpus de pesquisa foram construídas três categorias temáticas, a saber: Participação do familiar no tratamento, Dificuldade de adesão ao tratamento, e Adicção à droga como sintoma do vínculo adoecido, apresentadas a seguir.

\section{Participação do familiar no tratamento}

Tendo como ponto de partida a ideia de que a família é de vital importância na constituição da vida subjetiva do sujeito, os participantes deste estudo entendem que a presença dos familiares e/ou pessoas próximas aos usuários no espaço do tratamento é uma peça fundamental no cuidado em saúde mental. A relevância atribuída à participação de pessoas do convívio familiar do usuário nos grupos realizados no CAPSad fica evidente na fala dos entrevistados:

[...] A comorbidade, principalmente, quadros psicóticos que a gente precisaria talvez que o familiar estivesse presente [...] [P6].

[...] A questão familiar também é muito importante... O suporte familiar [...] é importante pra poder fazer esse vínculo com a família, né, de conscientizar a família. Acho que tem que ser todo mundo junto [...] [P7].

Apesar de concordarem que a inclusão de familiares dos usuários aporta ganhos ao tratamento, alguns obstáculos à efetivação dessa participação também foram mencionados pelos entrevistados:

[...] as famílias já não... Já tentaram várias formas de ajuda e não houve resposta do paciente, né? [P7].

Os familiares também trazem muitas dificuldades para os serviços, no sentido de que eles queriam que as coisas fossem muito rápidas. Eles se colocam numa posição de querer salvar aquele filho, aquele marido, né? Então, é uma cobrança muito grande em relação a eles, assim, sobre isso. Que isso também precisa ser olhado, né? Porque é muito cansativo para os familiares, por isso que precisa também ser olhado para como eles se colocam nessa relação com a substância, enfim. [P6].

[...] pessoas que estão o tempo todo com oscilação de humor, né, e também problemas familiares, né? [PS3]

$\mathrm{Na}$ maioria dos casos, os vínculos mantidos pelo usuário com a família nuclear são rompidos no processo de instalação da dependência da substância psicoativa, e aqueles que conseguem preservar os laços familiares geralmente mantêm relações permeadas por estresse e ambivalência afetiva. Assim, de acordo com a percepção dos entrevistados, as famílias frequentemente se apresentam desgastadas e desacreditadas quanto à sua efetiva possibilidade de aderir ao plano terapêutico e alcançar transformações positivas no decurso do tratamento, especialmente frente às recaídas que comumente acompanham essa trajetória. A dependência, como outros transtornos crônicos, tem um curso instável e sinuoso, sendo os altos e baixos, que às vezes culminam com as recidivas no sintoma, aquilo que há de mais previsível nesse cenário.

Na percepção dos participantes, quando um indivíduo adoece, os membros de sua família, direta ou indiretamente, adoecem juntos. Quando esse processo se cronifica e perdura por um tempo prolongado, tende a predominar o clima de desesperança e a falta de credibilidade na mudança. 0 ceticismo se instala porque os familiares frequentemente são expostos a situações crônicas conflitivas e degradantes, e experimentam dificuldades em encontrarem as soluções que anseiam para aplacar os conflitos e sanar a fragilidade dos vínculos.

Os entrevistados apontam também que frustrações e desgaste persistente potencializam sentimentos de angústia, cansaço e desalento. Assim, os dissabores experimentados de forma recorrente acabam por deixar todos em situação de acentuada vulnerabilidade. Para que o ambiente familiar se torne saudável, com padrões de relacionamento menos tóxicos, é necessário que exista uma rede de apoio que assegure acolhimento e fornecimento de instruções, que devem estar perenemente disponíveis para usuários e familiares. A melhora do ambiente familiar acontece quando a família finalmente recupera a vitalidade de suas forças restauradoras, podendo ativamente oferecer apoio e compreensão para seus integrantes mais vulneráveis, servindo de inspiração positiva para o indivíduo drogadito. Ao incluir o contexto 
familiar no cuidado integral ao usuário, intenciona-se ajudar a família a recuperar seu potencial de promover o amadurecimento de seus membros.

Os profissionais entrevistados entendem que o CAPSad, ao cumprir seu papel institucional, funcionando como rede de apoio tanto para o indivíduo como para a família, pode colaborar para o fortalecimento dos vínculos familiares. Isso também beneficia a qualidade dos vínculos estabelecidos com os profissionais da equipe de saúde, bem como com os outros usuários do serviço. A potencialização desses benefícios contribui para instaurar condições mais favoráveis para a adesão ao tratamento, na medida em que favorece a conscientização quanto à real magnitude das dificuldades enfrentadas e o compartilhamento de responsabilidades. Isso pode ser percebido nas falas dos participantes:

[...] Eu acho que é a conscientização, né, de toda essa questão aí que envolve a saúde mental mesmo, de poder orientar bem o paciente e de poder fazer um bom vínculo com ele, bem estruturado e fortalecido ao ponto de ele realmente aderir ao tratamento. Então, eu acho que o ponto de partida é a tomada de consciência. [P7].

Como o grupo de dependentes é recente, nós estamos esperando ter adesão ao grupo para a gente começar um grupo de familiares também. [P1].

\section{Dificuldade de adesão ao tratamento}

$\mathrm{Na}$ fala dos entrevistados se pode notar que a falta de adesão é destacada como um problema que pode se converter em ponto crítico para a efetividade do tratamento:

[...] esses pacientes que são obrigados a vir, é muito difícil ter adesão. Então, eu acredito que a adesão é a nossa maior dificuldade [...] [P1].

A maior dificuldade do paciente, quando ele traz a comorbidade da dependência, é a adesão ao tratamento [...] Eu acredito que, quando tem adesão, é bom o prognóstico [...] [P7]

[...] a maior dificuldade que a gente enfrenta, principalmente, não tanto de comorbidade, mas que são associadas ao uso de álcool e drogas, é a adesão. [...] Agora, a maioria não tem o apoio da família. É aquela família que já largou mão dele [...] [P2]

De acordo com a percepção de um entrevistado, um dos fatores que favorecem a adesão ao tratamento é a maximização da vinculação do usuário do CAPSad com a equipe multiprofissional:

[...] Pode ser um lugar de fazer vínculo social, e a ideia é sempre essa, que possa se vincular a outros, à equipe, funcionários e aos outros pacientes. É criar condições para que o sujeito consiga achar o caminho dele. [PS5].

Ao considerarem que o transtorno por uso de substâncias configura um problema crônico de saúde, que implica em sofrimento prolongado e persistente, os entrevistados admitem que as dificuldades de adesão ao plano individual de tratamento constituem um aspecto crítico do cuidado, porém asseveram que os embaraços e reveses fazem parte do percurso terapêutico de cada usuário. Os momentos sinalizadores de recuperação frequentemente se alternam com retrocessos no tratamento, quando o usuário volta a reincidir nos hábitos nocivos à saúde. É necessário compreender a natureza desses obstáculos e ter clareza na hora de abordá-los com usuários e familiares, buscando construir soluções compartilhadas para que as barreiras possam ser superadas.

Os entrevistados também destacaram que, ao trabalhar com as configurações vinculares, é fundamental pensar em oferecer estratégias grupais e oficinas que favoreçam a socialização e a participação ativa do usuário no serviço. 0 reconhecimento da necessidade de implementar um trabalho que privilegie o setting grupal aparece nas entrevistas como fator facilitador da adesão ao plano terapêutico:

[...] E até, se tivesse as oficinas, ele aderiria mais ao psicólogo, né. Aderiria mais ao psicólogo e melhoraria o tratamento, né [P4].

Assim, os entrevistados entendem que os grupos formados nos CAPSad contribuem para potencializar as propriedades mutativas do processo vincular, uma vez que as relações que se estabelecem entre participantes e profissionais, quando bem administradas, podem fortalecer os vínculos grupais, abrindo possibilidades para o alcance do insight, que é uma condição "sine qua non" para a superação da estereotipia e emergência da mudança:

[...] O próprio paciente, que está aí nesse grupo, nessa terapêutica, começa a internalizar também o cuidado, né [P4]. 


\section{Adicção à droga como sintoma do vínculo adoecido}

Os participantes identificaram como uma dimensão relevante no trabalho terapêutico investigar os primórdios do vínculo que o sujeito adicto estabeleceu com a substância psicoativa e como se estrutura seu padrão de vinculação com o ambiente e com o serviço:

[...] às vezes isso é um pouco complicado também, né, fazer com que eles vejam que a relação que eles têm com a substância é que é o problema, não a substância em si. É essa relação com a substância que a gente precisa mudar no ambiente em que eles estão inseridos, né? [P6].

Esse conhecimento possibilita encontrar modos mais eficazes de intervir terapeuticamente, conforme o depoimento de um dos profissionais entrevistados:

[...] Então, o processo é esse, escutar o sujeito. Não ficar preso aos fenômenos, aos comportamentos, mas ficar atento à relação dele com a própria vida, com a família, com os outros pacientes, com a gente. É um processo no qual a gente vai aprendendo a escutar. [P5].

Outro aspecto levantado pelos participantes do estudo foram as condições sociais objetivas nas quais o drogadicto se insere como membro de sua comunidade:

[...] Aí mistura tudo: o preconceito, a dificuldade familiar, a dificuldade de se manter abstinente, a dificuldade de se relacionar até com a própria sociedade. [P2].

[...] Às vezes é essa questão que eu falei pra você agora há pouco, da vulnerabilidade social que eles têm, que às vezes são pessoas que estão até em situação de rua. [P7].

Os entrevistados mencionaram que os entraves institucionais também são parte dos vínculos adoecidos, já que funcionam como barreiras que comprometem a qualidade e efetividade da assistência, uma vez que despotencializam os vínculos estabelecidos com a clientela do CAPSad. Os participantes consideram que é parte de seu trabalho manter a esperança de que podem ajudar o usuário a encontrar novas formas de se relacionar, na medida em que possa investir na criação de vínculos mais saudáveis capazes de fortalecer sua rede de apoio, mantendo-o inserido em sua família e comunidade, de modo que possa ser visto como sujeito ativo e responsável por seu processo de desenvolvimento, readquirindo assim o seu protagonismo como agente transformador de sua própria história.

\section{DISCUSSÃo}

A primeira categoria analisada, denominada Participação do familiar no tratamento, mostrou que a percepção dos psicólogos entrevistados no presente estudo acerca do suporte familiar corrobora dados reportados em outro estudo, que apontam que "a família é fundamental para o tratamento da dependência química, na medida em que é o elo que une os membros às diferentes esferas da sociedade e que está relacionada ao desenvolvimento saudável ou não de seus membros"18. Não obstante, os profissionais identificaram barreiras que restringem essa participação, privando o usuário dos seus potenciais benefícios.

Neste estudo, a percepção dos entrevistados indica que a família do usuário de substâncias frequentemente se apresenta exaurida ao sentir que o esgotamento de seus recursos de enfrentamento, o que a torna cética quanto ao seu próprio potencial de influenciar positivamente a evolução do tratamento. A atitude de descrédito em relação ao poder mutativo do tratamento se torna mais proeminente diante das situações de crise deflagradas pelas recidivas, que a bem da verdade são esperadas ao longo do tratamento ${ }^{7}$.

Esse processo, que tende a ser prolongado, frequentemente se arrasta por anos, drenando as energias do sistema familiar e consumindo as esperanças de todos os membros, vulnerabilizando especialmente aqueles que estão mais envolvidos com a busca de soluções para o problema. Por essa razão, os psicólogos entendem que as famílias necessitam receber suporte não apenas devido à sobrecarga física e psíquica, mas também para que elas possam fortalecer suas defesas e, a partir desse empoderamento, adquirir condições objetivas de modificar a organização vincular fragilizada.

Desse modo, ao refletirem sobre os desafios da inclusão dos familiares no tratamento, os participantes consideram que, quando os indivíduos são capazes de fazer uma avaliação mais realista da extensão e profundidade dos desafios que encontram pela frente, há maiores chances de não subestimarem nem superestimarem a envergadura dessa empreitada. 
A família é considerada pelos entrevistados como o grupo de socialização primária, responsável por garantir as condições de provimento das necessidades básicas do indivíduo. A família também oportuniza o primeiro contato social que o ser humano estabelece, mantendo um espaço de socialização e aprendizagem de regras, costumes, valores e conceitos. Esse espaço vincular pode ser predominantemente saudável ou patológico, dependendo dos modos que as pessoas privilegiam para solucionarem os conflitos despertados pela convivência.

É na dinâmica do convívio familiar que o indivíduo constrói e permanentemente desconstrói e reconstrói sua trama vincular. Se a família oferece um contexto de relacionamentos e interações saudáveis, os vínculos estabelecidos por seus membros tendem a ser genuínos e positivos, o que fortalece os processos de constituição da subjetividade. No entanto, quando a trama vincular intrafamiliar apresenta rupturas, descontinuidades e conflitos de difícil enfrentamento, o processo de vinculação pode se esgarçar e se estruturar de modo frágil e adoecido. Nesse caso, os relacionamentos se tornam tóxicos e disfuncionais.

Para os membros mais próximos do familiar adoecido, as consequências da experiência de conviver com o adicto podem se manifestar por meio de sintomas físicos e psicológicos. Por essa razão, na percepção dos entrevistados, a família do usuário de drogas configura um grupo vulnerável, que também necessita receber atenção e cuidados específicos ${ }^{18}$.

Os grupos que o indivíduo integra naturalmente no cotidiano, como a família e os colegas do ambiente de trabalho, alcançam uma posição privilegiada para que se formule uma compreensão de como as configurações vinculares familiares se manifestam no funcionamento psicológico do usuário. Nesse sentido, um conhecimento apurado das dinâmicas vinculares é essencial para o tratamento das dificuldades individuais ${ }^{7,8}$. Contudo, como observam os profissionais ouvidos neste estudo, nem sempre é possível contar com a presença efetiva dos familiares no contexto do tratamento.

A segunda categoria analisada foi a Dificuldade de adesão ao tratamento. Os fatores relacionados à não adesão do usuário ao plano terapêutico estabelecido pela equipe de saúde constituem um elemento crítico destacado nas falas dos participantes. Pode-se notar que a falta de uma postura colaborativa do usuário é vista como um problema crônico no manejo do tratamento, uma expressão recorrente de resistência que, se não for resolvida, pode se converter em barreira instransponível para a resolubilidade do plano individual de tratamento.

A adesão ao tratamento é entendida como o grau em que o usuário do serviço segue as recomendações dos profissionais de saúde e retorna ao serviço mantendo os princípios do tratamento indicado, seja ele medicamentoso ou comportamental ${ }^{19}$. Quando o indivíduo apresenta uma postura não colaborativa, que se traduz em dificuldades de aderir ao plano individual de tratamento, pode prejudicar seu prognóstico, seja porque aumentam suas chances de sucumbir a novos episódios de crise e reagudização dos sintomas, seja porque a recaída pode fragilizar ainda mais os vínculos com os familiares e seu ambiente social, agravando sua situação de vulnerabilidade.

Os entrevistados também se referiram a outro fenômeno recorrente na sua prática clínica, que é a alternância entre movimentos sinalizadores de possível estabilização com retrocessos, que podem culminar na recidiva. Essa dinâmica de altos e baixos expressa a resistência ao novo. Para entrar em contato com o novo, há necessidade de abandonar e despedir-se do velho, o que possibilita uma compreensão renovada, mas ao mesmo tempo gera ansiedade. Quando essa ansiedade é intensa e excede a capacidade de controle do sujeito, torna-se paralisante e reforça a resistência à mudança. Por isso, o usuário volta a reincidir nos hábitos nocivos à saúde.

Essa instabilidade provavelmente acompanhará o itinerário terapêutico de todos os usuários, o que torna os desfechos imprevisíveis, aumentando as chances de abalos disruptivos do vínculo terapêutico. A volatilidade dos ganhos terapêuticos é observada com frequência no cenário do tratamento dos transtornos por uso de substâncias, o que não significa que os esforços empreendidos anteriormente foram todos em vão. Persistência e tolerância à frustração são os maiores aliados do psicoterapeuta que lida com contextos de incerteza e 
imprevisibilidade. A esperança é a bússola mais indicada para atravessar os processos de sustentação do percurso de tratamento.

Além dessas dificuldades, os participantes relataram que nem sempre é possível contar com a colaboração dos familiares no tratamento. Isso acontece por diferentes razões, que vão desde uma indisposição ou animosidade com o membro adoecido até a indisponibilidade por motivos de trabalho, incompatibilidade de horários, acúmulo de responsabilidades e tarefas cotidianas, passando ainda por limitações físicas e/ou psíquicas dos cuidadores familiares, que frequentemente se apresentam ao serviço despotencializados e exauridos em suas energias físicas e psíquicas ${ }^{19,20}$.

Em relação ao usuário, muitas pessoas que enfrentam uma condição de dependência podem se sentir encarceradas nessa forma de ser ${ }^{10}$. Para abordá-las, é necessário recorrer à intervenção sistematizada e planificada pela equipe de saúde. É preciso que os profissionais de saúde estejam disponíveis para poderem criar e reinventar suas estratégias de abordagem em cada etapa do tratamento. Também é fundamental que, no decorrer do processo, essas estratégias delineadas no início possam ser revistas e reformuladas, com flexibilidade para criar vínculos sustentáveis, baseados na tolerância e na compreensão dos limites e possibilidades do usuário. Desse modo, é possível a emergência controlada da angústia que, quando acolhida e compreendida pelos profissionais, pode deflagrar o trabalho de elaboração psíquica.

Os entrevistados valorizaram intervenções, programas e oficinas pautados na estratégia grupal. Essa percepção corrobora outro estudo, que indica haver diversos tipos e modalidades de grupo disponíveis, destacando-se com mais força aqueles que têm como proposta a melhora dos sintomas apresentados pelos membros, em intervenções voltadas à resolução de conflitos que suscitam ansiedade e outros sintomas ${ }^{21}$. Para efetivar essa meta é importante que o terapeuta seja capaz de exercer adequadamente sua função de liderança na coordenação do grupo, fortalecendo sua condição simbólica de fiador e guardião das esperanças depositadas pelos integrantes.

A terceira categoria analisada foi denominada Adicção à droga como sintoma do vínculo adoecido. Em uma leitura ampliada do fenômeno, a drogadição pode ser vista também como um sintoma do mal-estar da sociedade contemporânea, que se caracteriza pelo incentivo ao individualismo desmedido e se pauta pela busca do prazer imediato, com marcada intolerância ao mínimo de desconforto. A evitação da dor psíquica é buscada a todo custo pela incorporação de objetos aplacadores de angústia ${ }^{9}$. A adoção de manobras evasivas cria um padrão de conduta no qual a descarga do impulso é prioritária, em detrimento do princípio de realidade e da capacidade de reflexão e elaboração da experiência.

Desse modo, o uso recorrente de substâncias segue a mesma lógica que movimenta as engrenagens da sociedade de consumo - uma resposta socialmente aprendida, segundo uma lógica segundo a qual toda dor pode ser obturada ou anestesiada com a incorporação indiscriminada de objetos e lenitivos químicos. Nesse cenário, cada indivíduo elege o seu objetodroga preferencial, lugar que pode ou não ser ocupado por uma substância psicoativa. As substâncias chamam a atenção porque prometem facilitar a via de acesso ao maior e mais pleno dos gozos, elidindo o desconforto provocado pela castração simbólica a que todos os sujeitos deveriam estar submetidos e que constituem a marca incontornável nos humanos.

No mito da liberdade absoluta de escolha se preconiza que o homem é livre para escolher, mas sem deixar de consumir, porque essa seria a única via de satisfação possível de suas necessidades básicas. Essa liberdade, paradoxalmente escravizante, encontra-se paralisada na expressão ambivalente do dependente, que se torna cativo de um padrão vincular tóxico e autodestrutivo. Por esse motivo, quando se traça as diretrizes do tratamento, se deve direcionar esforços para compreender a forma pela qual esses indivíduos se conectam à vida, às pessoas e às drogas, porque esse entendimento torna mais inteligível o tipo de vínculo estabelecido com a equipe e o tratamento de modo geral ${ }^{12}$. 
0 rompimento dos vínculos com o mundo do trabalho comparece nas falas dos entrevistados ora como fator causal, ora como consequência principal da escalada perniciosa do processo de dependência, o que aponta para a questão de que o usuário vai gradativamente acumulando prejuízos físicos, psicológicos e sociais, na medida em que a droga adquire prioridade em sua vida e passa a assumir uma posição de centralidade em seu cotidiano ${ }^{6} .0$ estigma social que o indivíduo carrega é outra barreira que dificulta a oportunidade de conseguir disputar uma vaga no mercado de trabalho ou até mesmo garantir sua permanência em um emprego de melhor qualidade. A baixa qualificação profissional e a situação de desemprego crônico são componentes recorrentes nas trajetórias de vida do usuário, contribuindo para desestabilizar a organização familiar, podendo desencadear crises que agravam a vulnerabilidade e intensificam o sofrimento psíquico.

As múltiplas rupturas vivenciadas pelo usuário ampliam a sensação de descontinuidade de seu processo vital, instaurando uma fratura em seu mundo psicossocial, o que contribui para perpetuar as dificuldades crônicas em lidar de forma madura e flexível com as demandas da realidade. Entretanto, não se pode perder de vista a capacidade do sujeito em assumir o protagonismo de seu viver, desde que receba o encorajamento e apoio apropriado para que possa retomar seu poder e controle pessoal sobre os acontecimentos de sua vida ${ }^{21,22}$.

0 trabalho do psicólogo nesse cenário deve se basear em uma escuta atenta do que o sujeito está comunicando, entendendo que ele também emite mensagens de forma cifrada por meio de seus sintomas. Ao decifrar essas mensagens latentes, buscamos compreender os padrões de comunicação e vinculação pelos quais se configuram suas relações com o meio e com sua própria subjetividade 23,24 .

Os entrevistados reconheceram que os entraves institucionais contribuem para a fragilização dos vínculos, funcionando como barreiras que comprometem a efetividade terapêutica da assistência e a construção de laços de empatia com o usuário do CAPSad. Os entraves identificados abrangem um leque amplo, dentre os quais se podem destacar: a formação profissional calcada em concepções moralizantes, naturalizantes e estigmatizantes, ainda fortemente inspirada no modelo biomédico 25,26 ; a desarticulação da rede de serviços disponíveis; os problemas locais que envolvem sobretudo uma dinâmica de trabalho marcada por sobrecarga; a escassez estrutural dos equipamentos de saúde e a deficiência crônica de recursos e falta de investimentos no setor saúde $27-29$.

\section{CONCLUSÃO}

Neste estudo foram realizadas entrevistas com profissionais de Psicologia que atuavam em quatro CAPSad, com vistas a conhecer as percepções sobre sua atuação junto à população de usuários de substâncias. Os resultados obtidos confirmam a importância do trabalho com grupos nos CAPSad, uma vez que os padrões de configurações vinculares podem ser melhor evidenciados e elaborados no setting grupal.

Os grupos operativos oferecem resultados terapêuticos que favorecem o processo vincular, podendo, desse modo, abrir novos caminhos para elaborar os conflitos e apontar possibilidades de ressignificação para os usuários do serviço. Ao priorizar o trabalho em grupos, buscando contemplar os princípios que norteiam os CAPSad desde sua criação, o serviço cumpre seu papel de fornecer um espaço de cuidado integral e socialização, promoção de integração familiar e incentivo da autonomia de seus usuários.

Para os entrevistados, a compreensão dos profissionais em relação às necessidades do usuário do serviço que se encontra em tratamento devido à drogadição deve partir do entendimento da relação peculiar que ele estabelece com a substância, ou seja, deve-se priorizar o modo como o sujeito se vincula ao seu objeto-droga de uso. Compreender os aspectos inconscientes da relação especial que se estabelece entre usuário e droga, entendendo-a como modelo de vínculo adoecido, significa considerar a adicção como um sintoma passível de ser tratado por meio do manejo psicoterapêutico. Trabalhar o vínculo em 
vez do sintoma ajuda a evitar que os comportamentos disfuncionais do usuário de drogas se tornem alvo de julgamentos preconceituosos e atitudes moralizantes. Desse modo, o vínculo entre o usuário e o serviço que oferece o tratamento pode também ser favorecido e, consequentemente, a oportunidade de se viver uma história de sucesso no enfrentamento da adicção pode ser consideravelmente ampliada.

Nas falas dos entrevistados, a participação dos familiares tem um papel fundamental no direcionamento do tratamento de pessoas com problemas de abuso de substâncias. Porém, quando tal inclusão não se efetiva na prática, o plano de tratamento proposto para abordar os problemas de vínculo encontrados na drogadição pode ser prejudicado e as metas estabelecidas podem não ser alcançadas.

Outro possível entrave que foi salientado pelos entrevistados diz respeito à dificuldade de adesão do usuário ao tratamento. Uma tentativa de resolução que pode ser promissora para equacionar essas barreiras identificadas pelos participantes tem sido o fortalecimento da rede de apoio e proteção criada pelo CAPSad.

Assim, o serviço pode se colocar na posição de articulador privilegiado dos recursos comunitários disponíveis, na medida que prioriza estrategicamente o trabalho realizado em grupos, em rede e no território, que visam a fortalecer os vínculos estabelecidos pelo usuário com a equipe do serviço. Ao deslocar o usuário do lugar da solidão individual para a solidariedade do enfrentamento coletivo, o CAPSad contribui para construir uma nova relação com a droga, a família e a sociedade.

Este estudo apresenta limitações, como amostra reduzida e delineamento transversal, sem possiblidades de generalização. Por outro lado, os resultados obtidos contribuem para o avanço do conhecimento produzido sobre a assistência psicológica no âmbito do CAPSad, além de fornecer pistas relevantes para fomentar futuras investigações.

\section{REFERÊNCIAS}

1. Ministério da Saúde (Br). Política Nacional sobre Drogas [Internet]. Brasília, DF: Conselho Nacional Antidrogas; 2005 [citado em 25 jan 2019]. Disponível em: http://www.ccs.saude.gov.br/saude_mental.pdf

2. Costa PHA, Mota DCB, Paiva FS, Ronzani TM. Desatando a trama das redes assistenciais sobre drogas: uma revisão narrativa da literatura. Cien Saude Colet. [Internet]. 2015 [citado em 25 jan 2019]; 20(2):395-406. Disponível em: http://www.scielo.br/pdf/csc/v20n2/1413-8123csc-20-02-0395.pdf

3. Ministério da Saúde (Br). A política do Ministério da Saúde para atenção integral a usuários de alcool e outras drogas [Internet]. Brasília, DF: Ministério da Saúde; 2004 [citado em 25 jan 2019]. Disponível em: http://bvsms.saude.gov.br/bvs/publicações/pns_alcool_drogas.pdf

4. Fernandes WJ. A importância dos grupos hoje. Rev SPAGESP [Internet]. 2003 [citado em 25 jan 2019]; 4:83-91. Disponível em: http://pepsic.bvsalud.org/pdf/rspagesp/v4n4/v4n4a12.pdf

5. Pichon-Rivière E. Teoria do vínculo. 2ed. São Paulo: Martins Fontes; 1986. p. 35-50.

6. Svartman B. Transubjetividade, sociedade atual: a importância das redes de apoio. Rev SPAGESP [Internet]. 2003 [citado em 01 fev 2019]; 4(4):29-36. Disponível em: http//pepsic.bvsalud.org/pdf/rspagesp/v4n4/v4n4a05.pdf

7. Souza J, Kantorski L, Mielke F. Vínculos e redes sociais de indivíduos dependentes de substâncias psicoativas sob tratamento em CAPS AD. SMAD, Rev Eletrônica Saúde Mental Álcool Drog [Internet]. 2006 [citado em 01 fev 2019]; 2(1):1-17. Disponível em: http://www.scielo.br/pdf/csc/v20n2/1413-csc-20-02-0395.pdf

8. Carniel IC. Possíveis intervenções e avaliações em grupos operativos. Rev SPAGESP [Internet]. 2008 [citado em 01 fev 2019]; 9(2):33-8. Disponível em: http://pepsic.bvsalud.org/pdf/rspagesp/v9n2/v9n2a06.pdf 
9. Carniel IC, Figueiredo MAC. O Esquema Conceitual, Referencial e Operativo (ECRO) de Enrique Pichon-Rivière. Rev Cient Eletr Estácio [Internet]. 2018 [citado em 13 mar 2019]; 11:169-78. Disponível

em: http://estacioribeirao.com.br/revistacientifica/arquivos/revista11/13.pdf 10. Brasiliano S. A adolescência e as drogas: reflexões para o profissional que atua com jovens e familiares. Vínculo [Internet]. 2006 [citado em 24 fev 2019]; 3(3):56-64. Disponível em: http://pepsic.bvsalud.org/scielo.php?script=sci_arttext\&pid=s1806-24902006000300007

11. Trinca RT, Sanches MV, Carvalho FA, Hochgraf PB, Ely P, Brasiliano S. Antropofagia e sustentabilidade: vínculos em mulheres dependentes de substâncias psicoativas. Vínculo [Internet]. 2013 [citado em 23 fev 2019]; 10(1):14-21. Disponível em: http://pepsic.bvsalud.org/pdf/vinculo/v10n1/a04.pdf

12. Pereira TTSO. Pichon-Rivière, a dialética e os grupos operativos: implicações para pesquisa e intervenção. Rev SPAGESP [Internet]. 2013 [citado em 18 fev 2019]; 14(1):21-9. Disponível em: http://pepsic.bvsalud.org/pdf/rspagesp/v14n1/v14n1a04.pdf

13. Terada DP, Celidonio NB, Silva ECS, Ávila LA. O desafio da drogadição. Vínculo [Internet]. 2012 [citado em 23 fev 2019]; 9(1):27-33. Disponível em: http://pepsic.bvsalud.org/pdf/vinculo/v9n1/a05.pdf

14. Favaro F, Paula SR. Dependentes químicos: o perfil da abstinência de drogas. Health Sci Inst. [Internet]. 2012 [citado em 31 mar 2019]; 30(1):41-3. Disponível em: https://www.unip.br/presencial/comunicacao/publicacoes/ics/edicoes/2012/01_janmar/V30_n1_2011_p41-43.pdf

15. Santi PLR. Sobre as adicções: a incapacidade de estar só. IDE [Internet]. 2009 [citado em 31 mar 2019]; 32(48):215-9.

Disponível

em

http://pepsic.bvsalud.org/pdf/ide/v32n48/v32n48a24.pdf

16. Gil AC. Como delinear um levantamento. In: Gil AC. Métodos e técnicas de pesquisa social. 6ed. São Paulo: Atlas; 2008. p. 111-128.

17. Bardin L. Organização da análise. In: Bardin L. Análise de conteúdo. 3ed. São Paulo: Edições 70; 2011. p. 95-102.

18. Braun LM, Dellazzana-Zanon LL, Halpern SC. A família do usuário de drogas no CAPS: um relato de experiência. Rev SPAGESP [Internet]. 2014 [citado em 14 mar 2019]; 15(2):122-44. Disponível em: http://pepsic.bvsalud.org/pdf/rspagesp/v15n2/v15n2a10.pdf

19. Borba LO, Maftum MA, Vayego SA, Mantovani MF, Felix JVC, Kalinke LP. Adherence of mental therapy for mental disorder patients to drug health treatment. Rev Esc Enferm USP [Internet]. 2018 [citado em 15 mar 2019]; 52:e03341. Disponível em: http://www.scielo.br/pdf/reeusp/v52/1980-220X-reeusp-52-e03341.pdf

20. Carniel IC, Moreira AP, Gonçalves Neto F, Gonçalves L, Antonio L, Vitrani L. As representações do familiar cuidador em relação ao cuidado em saúde mental. Saúde Transform Soc. [Internet]. 2015 [citado em 22 mar 2019]; 6(3):76-87. Disponível em: https://www.redalyc.org/articulo.oa?id=265345667009

21. Campos-Brustelo TNC, Bravo FF, Santos MA. Contando e encantando histórias de vida em um centro de atenção psicossocial. SMAD, Rev Eletrônica Saúde Mental Álcool Drog [Internet]. 2010 [citado em 01 fev 2019]; 6(1):1-11. Disponível em: http://pepsic.bvsalud.org/pdf/smad/v6n1/07.pdf

22. Barros ML, Calmon TF, Santos MA, Rigobello LX. Uma experiência de grupo operativo em um centro de atenção psicossocial: construindo novas possibilidades. In: Santos MA, Simon CP, Melo-Silva LL, organizadores. Formação em psicologia: processos clínicos. São Paulo: Vetor; 2005. p. 235-53.

23. Santos MA, Scatena L, Ferriani MGC, Peres RS. Grupo operativo com adolescentes em um núcleo da assistência social: a questão da identidade de gênero. Rev SPAGESP [Internet]. 2015 [citado em 03 jan 2019]; 12(1):51-8. Disponível em: http://pepsic.bvsalud.org/pdf/vinculo/v12n1/v12n1a08.pdf 
24. Santos MA, Scatena L, Dias MGRO, Pillon C, Miasso AI, Souza J, Petean EBL, Zanetti ML. Grupo operativo com professores do ensino fundamental: integrando o pensar, o sentir e o agir. Rev SPAGESP [Internet]. 2016 [citado em 03 jan 2019]; 17(1):39-50. Disponível em: http://pepsic.bvsalud.org/pdf/rspagesp/v17n1/v17n1a05.pdf

25. Furlan V, Ribeiro SFR. A escuta do psicoterapeuta em grupo com pessoas em sofrimento mental atendidas em Centro de Atenção Psicossocial (CAPS). Vínculo [Internet]. 2011 [citado em 23 fev 2019]; 8(1):22-9. http://pepsic.bvsalud.org/pdf/vinculo/v8n1/a05.pdf

26. Bezerra E, Dimenstein M. Os CAPS e o trabalho em rede: tecendo o apoio matricial na atenção básica. Psicol Cienc Prof. [Internet]. 2008 [citado em 30 mar 2019]; 28(3):632-45. Disponível em: http://www.scielo.br/pdf/pcp/v28n3/v28n3a15.pdf

27. Larentis CP, Maggi A. Centros de Atenção Psicossocial Álcool e Drogas e a psicologia. Aletheia [Internet]. 2012 [citado em 30 mar 2019]; 37(1):121-32. Disponível em: http://pepsic.bvsalud.org/pdf/aletheia/n37/n37a09.pdf

28. Bernardi AB, Kanan LA. Características dos serviços públicos de saúde mental (CAPSI, CAPSAD, CAPS III) do estado de Santa Catarina. Saúde Debate [Internet]. 2015 [citado em 25 mar 2019]; 39(107):1105-16.

http://www.scielo.br/pdf/pcp/v28n3/v28n3a15.pdf

Disponível em:

29. Ribeiro JM, Moreira MR, Bastos FI, Inglez-Dias A, Fernandes FMB. Acesso aos serviços de atenção em álcool, crack e outras drogas: o caso do município do Rio de Janeiro, Brasil. Ciênc Saúde Colet [Internet]. 2016 [citado em 25 jan 2019]; 21(1):71-81. Disponível em: http://www.scielo.br/pdf/sdeb/v39n107/0103-1104-sdeb-39-107-01105.pdf

\section{CONTRIBUIÇÕES}

Isabel Cristina Carniel foi responsável pela orientação, concepção, delineamento, análise, interpretação dos resultados e redação. Tamys Duran e Ana Carolina da Silva Oliveira colaboraram com o levantamento bibliográfico, coleta, análise, interpretação dos dados e redação. Sandra Cristina Pillon atuou na análise e revisão. Manoel Antônio dos Santos contribuiu com a concepção, delineamento, análise e interpretação dos resultados, redação e revisão.

\section{Como citar este artigo (Vancouver)}

Carniel IC, Duran T, Oliveira ACS, Pillon SC, Santos MA. Percepção de profissionais de psicologia sobre a assistência oferecida aos usuários de Centros de Atenção Psicossocial. REFACS [Internet]. 2020 [citado em inserir dia, mês e ano de acesso]; 8(Supl. 1X):575-589. Disponível em: inserir link de acesso. DOI: inserir link do DOI

\section{Como citar este artigo (ABNT)}

CARNIEL, I. C.; DURAN, T.; OLIVEIRA, A. C. S.; PILLON, S. C.; SANTOS, M. A. Percepção de profissionais de psicologia sobre a assistência oferecida aos usuários de Centros de Atenção Psicossocial. REFACS, Uberaba, MG, v. 8, p. 575-589, 2020. Supl. 1. Disponível em: inserir link de acesso. Acesso em: inserir dia, mês e ano de acesso. DOI: inserir link do DOI.

\section{Como citar este artigo (APA)}

Carniel, I. C., Duran, T., Oliveira, A. C. S., Pillon, S. C. \& Santos, M. A. (2020). Percepção de profissionais de psicologia sobre a assistência oferecida aos usuários de Centros de Atenção Psicossocial. REFACS, 8(Supl. 1), 575-589. Recuperado em: inserir dia, mês e ano de acesso de inserir link de acesso. DOI: inserir link do DOI. 